\title{
De transformatie van kennis voor klimaatadaptatie ${ }^{*}$
}

\author{
Daan Boezeman
}

\begin{abstract}
Wetenschappelijke kennis speelt een cruciale, maar problematische rol in het vaststellen van klimaatrisico's en dus in klimaatadaptatie. Dat roept de vraag op hoe kennisclaims voor adaptatiebeleid worden gemaakt. In dit artikel staan de productie van gezaghebbende en relevante kennisclaims in de tweede Deltacommissie, regional waterbeheer en hitte in steden centraal. Beargumenteerd wordt dat het gangbare vraag-en-aanbodmodel van de wetenschapper die pakketjes toepasbare kennis produceert die de beleidsmaker gebruikt, niet opgaat. De studie laat zien hoe het 'wicked' probleem klimaatverandering getemd en hanteerbaar wordt gemaakt in adaptatie. In dat proces transformeert kennis over klimaatverandering. Het artikel biedt een begrippenapparaat om transformatie te analyseren. Transformatie heeft een januskop. Terwijl transformatie klimaatverandering lokale betekenis geeft om concrete adaptieve acties mogelijk te maken, leidt het ook tot blindheden voor klimaatrisico's. Transformaties worden beïnvloed door de doelen en instituties in beleidsvelden. Om de problemen van blindheid en cognitieve padafhankelijkheid het hoofd te bieden, is meer institutionele verandering nodig dan waar de huidige benadering van kennisco-creatie en meekoppelen voor staat.
\end{abstract}

\section{Klimaatadaptatie als wicked probleem}

Klimaatadaptatie krijgt steeds meer aandacht zoals blijkt uit de parade van Europese, nationale of stedelijke adaptatiestrategieën. Klimaatverandering geldt als een schoolvoorbeeld van een 'wicked' probleem (Metze \& Turnhout, 2014): ongestructureerde problemen waarbij consensus over waarden en feiten ontbreekt. Problemen die nooit definitief oplosbaar zijn. Wetenschap en beleid zijn bij klimaatadaptatie onlosmakelijk met elkaar verbonden, maar hebben een inherent moeizame relatie. Zo is kennis cruciaal voor het identificeren van klimaatrisico's en het vormgeven van adaptatiebeleid. Die kennis is echter onzeker, complex en mogelijk controversieel en soms onbruikbaar voor beleidsmakers. Tegelijk beïnvloedt klimaatverandering op talloze wijzen de leefomgeving en sluimeren er belangenconflicten. Vanuit dat perspectief is het niet verrassend dat evaluaties stellen dat klimaatkennisgebruik in besluitvorming traag en beperkt is (Kirchhoff, Lemos, \& Dessai, 2013).

* Dr. D.F. Boezeman is onderzoeker bij het Planbureau voor de leefomgeving en gastonderzoeker bij de sectie Geografie, Planologie en Milieu van de Radboud Universiteit. 
Om deze problemen het hoofd te bieden vergt klimaatadaptatie volgens velen (Termeer et al., 2011) andersoortige sturingsstrategieën. De beleidswetenschappelijke literatuur heeft met haar vraag-en-aanbodmodel veel problemen blootgelegd (bijv. Sarewitz \& Pielke, 2007). In Nederland wordt daarom met institutionele innovaties geprobeerd de uitwisseling tussen klimaatwetenschappelijk aanbod en vraag vanuit adaptatiebeleid te verbeteren. Meekoppelen en kennisco-creatie zijn daarbij centrale concepten in zowel toegepaste klimaatonderzoeksprogramma's als adaptatiebeleid. Kort gezegd komen die sturingsconcepten er op neer dat vraaggestuurde kennisontwikkeling wordt versterkt door wetenschappers en beleidsmakers bij elkaar te brengen in kennisproductie (co-creatie) voor adaptatievraagstukken aansluitend bij lopende beleidsdossiers (meekoppelen).

Denken in termen van beleidsvraag en kennisaanbod heeft een keerzijde. Het richt de blik direct op de organisatie van kennis-en-beleidsarrangementen, maar voor de precieze totstandkoming van de kennisclaims en adaptatieproblemen zélf is weinig aandacht. Klimaatverandering raakt verschillende beleidsdomeinen. Het biedt daarom een uitgelezen kans om te vergelijken hoe klimaatverandering door die domeinen wordt opgenomen en vertaald in adaptatiebeleid. In dit artikel wordt een dubbele vraag beantwoord: Hoe wordt het fenomeen klimaatverandering in verschillende beleidsdomeinen vertaald in betekenisvolle adaptatieproblemen en gezaghebbende kennisclaims? Welke lessen zijn daaruit te trekken voor de sturing van kennisproductie voor adaptatie?

Op basis van kwalitatief casestudy-onderzoek naar kennisproductie in de Commissie-Veerman, hitteprojecten in steden en regionaal waterbeheer bekritiseer ik in dit artikel eerst het idee dat kennis wordt 'overgezet' naar beleid. Kennisclaims en problemen transformeren in het proces van klimaatadaptatie. Daarna beschouw ik kritisch de consequenties hiervan, ook in het licht van de twee populaire sturingsconcepten co-creatie en meekoppelen.

\section{Een constructionistische kijk op kennis en beleid}

\section{Vraag-en-aanbod modellen}

In de beleidswetenschappelijke literatuur over kennis en beleid is het vraag-enaanbodmodel gangbaar (Sarewitz \& Pielke, 2007). Wetenschap en politiek zijn twee gescheiden werelden. Door verschillende beloningsstructuren, communicatieproblemen en logica's van die werelden wordt wetenschappelijke kennis lang niet altijd gebruikt om het beleidsproces rationeler te maken. Samenwerkingsarrangementen zijn nodig om het zogenaamde gat tussen beiden te overbruggen, relevante wetenschappelijke inzichten te produceren en kennis actief over te plaatsen.

Hoewel dit model intuïtief klinkt en wetenschapsbeleid sterk beïnvloedt, is er vanuit de constructionistische hoek fundamentele kritiek. Ik vat die kritiek hier in drie punten kort samen (voor een uitgebreide kritiek en conceptueel alternatief zie Boezeman, 2015). Ten eerste zijn de grenzen tussen de werelden wetenschap en politiek contingent, en lang niet zo homogeen, tweevoudig en stabiel als ze worden voorgesteld. Ten tweede is de wetenschap geen monopolistische produ- 
cent en het beleid geen passieve ontvanger, maar worden kennisclaims in wisselwerking geproduceerd. Ten derde is er kritiek op het beeld van 'pakketjes kennis' die, nadat ze ontdekt zijn in de wetenschappelijke praktijk, niet veranderen als die kennis wordt 'toegepast'.

\section{Constructionistisch alternatief}

Het constructionistische perspectief 'bekijkt de praktijken waarin claims over de natuurlijke wereld worden samengesteld en de status van realiteit verkrijgen' (Jasanoff \& Wynne, 1998, p. 4). Jasanoff (2010, p. 248) benadrukt dat gezaghebbende voorstellingen over het klimaat en zijn effecten ontstaan in wisselwerking tussen feitenvorming en betekenisverlening. Ik kies bij die analyse het conceptuele kader van sociale werelden (Clarke \& Star, 2008) als startpunt. Sociale werelden zijn groepen georganiseerd rond bepaalde activiteiten, die een discursief systeem, een serie hulpbronnen en een set standaardprocedures voor handelen delen. Sociale werelden geven actoren identiteit en zijn voortdurend bezig de legitimiteit van zichzelf, hun problemen en van hun handelswijze te bevechten door grenzen te bewaken ten opzichte van andere sociale werelden. Voorbeelden zijn de klimaatwetenschap, de hydrologie, de stadsplanning, de politiek of het recht. Sociale werelden ontmoeten elkaar in organisaties of projecten rond kwesties waarin ze een gedeeld belang of betrokkenheid hebben.

In navolging van Jasanoff \& Wynne (1998) deel ik kennisproductie op in drie samenhangende activiteiten. De eerste activiteit is het proces van (re-)framing. Betrokken sociale werelden herformuleren het gezamenlijke 'wicked' probleem waarvoor ze zich gesteld zien in hanteerbare kwesties. De tweede activiteit betreft het deconstrueren en reconstrueren van klimaatkennisclaims die dienstbaar zijn voor het specifieke adaptatieprobleem waarmee zij zich geconfronteerd zien. De derde activiteit is het stabiliseren van de legitimiteit en autoriteit van die claims, door hen te laten voldoen aan de eisen van de verschillende betrokken sociale werelden.

\section{Methodologie}

Hoewel het kennisproductieproces veel theoretische aandacht krijgt, is er geen goed conceptueel apparaat om de kennisclaims zelf te kunnen beschrijven (zie echter Shackley \& Wynne, 1996). Grounded theory (Charmaz, 2014; Clarke \& Star, 2008) op basis van drie casestudies vormde de methodologische basis om te begrijpen wat er met klimaatkennis in adaptatieprojecten gebeurt. De cases zijn gevarieerd zodat zij verschillende beleids- en wetenschapsvelden omvatten. Het zijn 'oude' (overstromingen) en 'nieuwe' (hitte) problemen. Ook verschillen de cases in de mate waarin sterk gecodificeerde uitwisselingsprocedures bestaan tussen wetenschap en beleid (waterbeheer versus stadsplanning). Rijke data werd verzameld door middel van ruim veertig interviews met betrokken sleutelpersonen, documenten, participatieve observatie en actieonderzoek (details in Boezeman, 2015). Door voortdurend vergelijken is gedurende het onderzoek een set van vijf concepten ontwikkeld om te kunnen begrijpen wat er precies met kennis en problemen gebeurde in mijn casus. Die concepten staan centraal in de volgende paragrafen. 


\section{Transformatie van klimaatkennis en adaptatieproblemen}

De tweede Deltacommissie presenteerde in 2008 aan het kabinet haar wetenschapsgebaseerde visie om Nederland op de lange termijn veilig te houden voor klimaatverandering (zie Boezeman, Vink, \& Leroy, 2013). De staatscommissie onder voorzitterschap van Cees Veerman was samengesteld uit personen uit verschillende wetenschappelijke disciplines, het bedrijfsleven, beleidsvelden en de politiek. Een reeks van sociale werelden was vertegenwoordigd aan de vergadertafel van de commissie. De Deltacommissie vormde een cruciale casus in de transformatie van, enerzijds, de betekenis van klimaatverandering voor Nederland en, anderzijds, voor het begrip van hoe de aanpassing aan klimaatverandering strategisch zou moeten worden bestuurd. Dat was opvallend omdat veel gepresenteerde beleidsopties non-incrementeel waren, maar vooral omdat de adviezen tot institutionele verandering leidden en gekoppeld waren aan een voor de commissie geconstrueerd klimaatscenario. Dat scenario ging verder dan de toen gebruikelijke projecties van het IPCC en KNMI.

De tweede casus, Droge Voeten 2050, betrof een adaptatieadviesproject voor regionaal waterbeheer in Groningen en Drenthe (zie Boezeman, Vink, Leroy, \& Halffman, 2014). Dit project bracht een intergouvernementele werkgroep bijeen die een advies moest uitbrengen voor de langetermijngevolgen van klimaatverandering, bodemdaling en landgebruik. Daarnaast moest zij maatregelen voorstellen voor regionale klimaatadaptatie. De lange traditie en zijn sterk geïnstitutionaliseerde karakter maakt het regionaal waterbeheer tot een interessante casus om te bestuderen hoe bestaande instituties reageren op de nieuwe eisen die klimaatverandering met zich meebrengt. Klimaatverandering en klimaatadaptatie werden in deze casus sterk verengd, zodat partijen meer zekerheid over de procesuitkomst zouden hebben en klimaatverandering tot niet te veel aanpassing van bestaande beleidsprocessen en -structuren zou leiden.

In de derde en laatste casus werd onderzocht hoe beleidsrelevante kennis werd geconstrueerd over het opkomende fenomeen stedelijke opwarming in Nederland in het algemeen, en in meer detail in Rotterdam, Arnhem en Utrecht (zie Boezeman, 2016). Met de toenemende aandacht voor klimaatverandering in Nederland kreeg ook het stadsklimaat (hernieuwde) aandacht in stedelijke ontwikkelingsstrategieën. Hoewel het een oud onderwerp in de urbane meteorologie betrof, was de circulatie en institutionalisering van kennis in de Nederlandse planningspraktijk zeer beperkt. In die adaptatiedebatten stond dan ook centraal óf dit een legitiem overheidsprobleem was en, zo ja, van welk type overheidsprobleem er dan sprake was? Het gevolg was een volatiel proces waarin sociale werelden zoals stedelijke ruimtelijke ordening, urbane klimatologie, volksgezondheid en politiek nieuwe uitwisselingsrelaties aangingen. Wat hitte voor de stad betekende en wat oplossingsrichtingen waren, was divers en sterk afhankelijk van sociale werelden die het fenomeen wilden toe-eigenen of juist op afstand houden.

In alle drie de casus bleek het gangbare beeld van pakketjes wetenschappelijke kennis die moeten worden overgezet naar de beleidswereld niet op te gaan. Het 'wicked' probleem klimaatverandering werd door wetenschappers, beleidsmakers en andere belanghebbenden getemd en hanteerbaar gemaakt voor het beleidsveld waar klimaat een onderdeel van werd gemaakt. Incrementeel en stapsgewijs poog- 
den zij 'klimaat' tot een normaal onderdeel te maken van, en te doen passen in, reeds bestaande beleidsprocessen. Ik stel dat het daarbij beter is om van transformatie van zowel klimaatkennis als klimaatadaptatie te spreken. Transformeren was een delicaat proces van deconstrueren en reconstrueren wat klimaatverandering is en betekent voor het beleidsveld in kwestie. Daarbij presenteerden waterbeheerders klimaatverandering zodanig dat zij paste binnen bijvoorbeeld een stochastische overstromingsstudie. In de casus stedelijke opwarming werden claims geproduceerd die andere beleidsafdelingen moesten verleiden om tot adaptieve acties over te gaan. Daarbij maakten actoren gebruik van bestaande en gezaghebbende theorieën, datasets en procedures, en anticipeerden ze of afwijkingen de steun van sociale werelden zouden houden. Past deze voorstelling binnen wat in de meteorologie of hydrologie, belichaamt door gereputeerde instituten als respectievelijk het KNMI en Deltares, acceptabel is? Houdt de productiewijze van kennisclaims juridisch stand voor de Raad van State? In dat proces transformeerde het fenomeen klimaatverandering van hoedanigheid. Vijf concepten - reductie, extensie, retorisch verpakken, herdefiniëren en modificeren - maken de analyse van transformatiemomenten mogelijk. Geen van die begrippen is dominant. Ze werken in de praktijk op elkaar in, of volgen elkaar op.

\section{Reductie}

Het begrip reductie verwijst naar het bewust of onbewust ontkoppelen van sommige elementen uit de constructie van klimaatverandering. De potentieel eindeloze reeks van elementen die impacts van klimaatverandering omvatten worden daarbij teruggebracht. In het geval van de Deltacommissie is het proces van het construeren van claims over de plausibele bovengrens van zeespiegelstijging een voorbeeld. Door een reeks van stappen werd de brede set van plausibele zeelspiegelstijgingen, afgeleid uit talloze klimaatmodellen, teruggebracht tot één getal in een kennisclaim uit het persbericht dat 'rekening [moet] worden gehouden met een zeespiegelstijging van 0,65 tot 1,30 meter in 2100 (...). Meer dan tot nu toe werd aangenomen.' In dat proces koppelde de commissie niet alleen bijvoorbeeld het zogenaamde gravitatie-effect los van de relevante factoren, maar positioneerde ze deze claim zodanig dat zij mede gemaakt is door, en de steun heeft van, de gereputeerde klimaatinstituten KNMI en IPCC. Die voorstelling van klimaatverandering kon Nederland aan, claimde de commissie, mits het Nederlandse adaptatiebeleid vormgegeven zou worden volgens de agenda en institutionele reorganisaties die de commissie voorstelde. Ook in het regionaal waterbeheer werd klimaatverandering uiteindelijk teruggebracht tot één enkel getal.

\section{Extensie}

Extensie is juist het tegenovergestelde van reductie. Extensie verwijst naar associatie van nieuwe elementen aan het construct klimaatverandering. Een eerste vorm is het substantiëren van een bewering met meer (typen) bewijslast of oplossingen, zodat zij meer wetenschappelijke kracht of relevantie krijgt. Bijvoorbeeld door zowel modelberekeningen, satellietdata als bakfietsmetingen van het stedelijk hitte-eiland te presenteren, of juist de relevantie ervan te koppelen in termen van ervaren overlast van burgers of volksgezondheidseffecten. Een andere vorm 
is het verbreden van de scope van het probleem. Zo probeerden, maar faalden, belanghebbenden in de watermanagement-casus om naar meer te kijken dan de effecten van klimaatverandering op het overlopen van dijken. De Deltacommissie slaagde wel in haar opzet om de betekenis van haar opdracht te veranderen van de kust naar de hele Nederlandse delta, om zo over Nederland als geheel te kunnen adviseren.

\section{Retorisch verpakken}

Retorisch verpakken verwijst naar het inkleden van kennisclaims in uitvoerige argumentatie om de overtuigingskracht van die claim te versterken. In alle gevallen wordt geprobeerd duidelijk te maken dat het niet slechts een commissie of een projectgroep is die spreekt, maar dat er namens een heel netwerk van sociale werelden wordt gesproken die de geloofwaardigheid garanderen. Zo claimde men bijvoorbeeld dat getoetste methoden gebruikt waren of dat de voorliggende kennisclaim betrouwbaarder was dan alternatieven. Achter de schermen wordt verkend welke constructen steun genieten, en op welke wijze een gemaakte claim steun zal behouden. Als iets niet geadviseerd wordt, bijvoorbeeld het door Balkenende gesteunde idee van kunstmatige eilanden voor de Hollandse kust, zijn substantiële passages, appendices en conversaties nodig. Soms is er achter de schermen steun voor sommige typen adaptieve maatregelen en voor andere niet. De effecten van klimaatverandering op het Lauwersmeer of dijkstabiliteit worden dan gedissocieerd en uitgesteld om in de toekomst nader onderzocht te worden, vaak met een beroep op 'onzekerheden'.

\section{Herdefiniëren}

Herdefiniëring verwijst naar het proces waarin de representatie van klimaatverandering wordt omgewerkt en weergegeven in een andere categorie. Door herdefiniëring verandert het raamwerk en daarmee de relaties tussen elementen waarmee een construct is opgebouwd. De sets van indicatoren of relevante adaptatieopties veranderen daarmee. In de studie naar stedelijke opwarming volgden veranderingen elkaar in hoog tempo op. Rond 2007 werd de kwestie 'stedelijke hitte' geherdefinieerd van een variabele die langjarige temperatuurreeksen beïnvloedt, en waarvoor gecorrigeerd moet worden, in een klimaatveranderingsfenomeen waaraan Nederland zich zou moeten aanpassen. Hoewel eerst, in een door wetenschap gedomineerde praktijk, de echtheid werd bewezen, beïnvloedde gaandeweg het type beleidsdomein dat de logische probleemeigenaar moest zijn hoe dit probleem geframed werd. Of dit een stedelijk ruimtelijk ordeningsprobleem zou zijn of een volksgezondheidsrisico maakte uit welke klimaatimpactkennis de projecten produceerden. De herdefinitie als risico-object in de Rotterdamse adaptatiestrategie maakte het mogelijk om kwetsbare populaties en de infrastructuur te visualiseren in een worst case klimaatscenario voor 2050.

\section{Modificeren}

Modificatie verwijst naar veranderingen in de dimensies of van sommige elementen waarmee een kennisclaim is geconstrueerd. Deze veranderingen zijn soms erg subtiel. Een eerste vorm van modificatie betrof de vervanging van de dimensie 
tijd door de dimensie ruimte in de casus stedelijke opwarming. Onder invloed van het concept hitte-eiland, en de geschiktheid daarvan voor ruimtelijk zoneringsbeleid, veranderde het adaptatieprobleem van aanpassing aan hete steden in de toekomst naar een ruimtelijk gedifferentieerd hier-en-nu probleem waarin sommige delen van de stad warmer zijn dan anderen. In het Droge Voeten 2050-project is een andere vorm van modificatie te observeren. Door met de lens 'klimaatverandering' het verleden te herinterpreteren veranderden de claims over de húídige overschrijdingskansen van dijken. Zo werd in het stochastische model bijvoorbeeld de dataset met zeewaterstanden aangepast voor klimaatverandering in het verleden. Ook werd een factor toegevoegd over het gelijktijdig voorkomen van hoge buitenwaterstanden en hevige regenval. Dat laatste was een hot topic in een gezamenlijk project van Deltares, KNMI en Noorderzijlvest over de vraag hoe klimaatverandering invloed heeft op extreme weersomstandigheden zoals bij noordwesterstormen.

\section{Transformatie heeft een januskop}

Transformatie heeft een januskop. Aan de ene kant zorgt transformatie ervoor dat klimaatverandering betekenis krijgt in lokale betekenissystemen zodat adaptatie mogelijk wordt. Zoals James Scott (1998) zo overtuigend liet zien, is de simplificatie en standaardisatie van de natuur of maatschappij in 'leesbare' en bestuurbare formaten het centrale probleem van sturing en staatsvorming. Transformatie brengt sommige voorstellingen van het klimaat binnen ons collectieve blikveld en stelt het in staat om klimaateffecten nauwkeurig te kunnen meten, monitoren en manipuleren. Aan de andere kant sluit transformatie af en leidt het tot blindheid voor sommige elementen van klimaatverandering. Transformatie helpt het proces dat Steve Rayner (2012) 'de sociale constructie van onwetendheid' noemt beter te begrijpen. Omdat, bewust of onbewust, sommige klimaatrisico's onderbelicht blijven, brengt transformatie in de praktijk dus een kostprijs mee van potentieel slechte aanpassing.

Er zijn verschillende voorbeelden te geven voor de stelling dat transformatie tegelijk elementen van klimaatverandering zichtbaar als onzichtbaar maakt voor beleid. Door het advies van de Deltacommissie werd de veelomvattende Nederlandse agenda uit het Adaptatieprogramma Ruimte en Klimaat getransformeerd naar een agenda gedomineerd door waterveiligheid en droogte. Dat leidde tot veel en diepgaande kennisproductie van de klimaateffecten op de Nederlandse watersector. Echter, de adaptatiestrategie die resulteerde uit het advies van de commissie werd ook flink bekritiseerd, omdat het blinde vlekken had voor onder meer de gezondheids- en infrastructuurrisico's van klimaatverandering (zie het Rekenkamerrapport uit 2012). In de casus regionaal waterbeheer is te observeren hoe de specifieke transformatie van klimaatverandering tot blindheid leidde voor alles dat buiten het blikveld viel van kwantitatieve kansen dat water over dijken zou lopen. Dat waren gevolgen buiten die beperkte overstromingsscope, zoals op waterkwaliteit of overstromingen in de zomer. Maar het waren ook gevolgen binnen die scope, zoals op de toenemende kans op dijkfalen. De casus over stedelijke 
opwarming laat zien hoe sommige klimaateffecten, zoals het effect op luchtkwaliteit, uit de constructie van kennis werden verwijderd. De Nederlandse probleemframing van 'stedelijke thermostaat' en 'kwetsbare ouderen' is sterk op technischstedenbouwkundige en fysiologische kennis gericht, maar laat sociaal-culturele kennis van klimaatkwetsbaarheden en oplossingsrichtingen buiten beeld (vgl. Klinenberg, 2015).

De drie casus maken duidelijk dat de transformatie van klimaatverandering wordt beïnvloed door de doelen en verpatroonde preoccupaties van bestaande beleidsvelden. Kennisclaims transformeren zodat ze passen binnen de eisen en mogelijkheden van een beleidsveld. Bruikbare kennis hangt af van de geïnstitutionaliseerde praktijken van beleidsvelden en van de wijze waarop dominante actoren de kwestie klimaatverandering in iets hanteerbaars voor hun beleidsveld definiëren. In de ruimtelijke planning moest klimaatverandering 'verruimtelijkt' worden om relevant te zijn en in de overstromingsrisicobeoordeling moesten klimaateffecten worden 'geprobabiliseerd'. De casus Deltacommissie laat het belang zien van het positioneren van kennis ten opzichte van een historisch gegroeide constellatie van ideeën en belangrijke actoren. In de casus regionaal waterbeheer werd klimaatverandering getransformeerd om in de hydrologische beoordelingsmachinerie te passen. De sterk gecodificeerde interface tussen wetenschap en beleid zorgde daar voor zekerheid in het transformatieproces, maar ook voor rigiditeit. De modificaties, herdefinities en extensies in de casus stedelijke opwarming volgden elkaar in snel tempo op. De voortdurende erosie en herbouw van legitimiteit waren belangrijke factoren in dat proces.

\section{Meekoppelen en co-creatie: kritisch (onder)belicht}

Twee sturingsconcepten zijn momenteel leidend voor klimaatadaptatie. Enerzijds worden klimaatonderzoeksprogramma's vormgegeven zodat geproduceerde kennis dichter aansluit bij de behoeften van beleidsmakers: kennisco-creatie. Anderzijds zijn sturingsstrategieën gebaseerd op 'mainstreaming' in, en meeliften op, reeds bestaande beleidsinitiatieven: dat wordt meekoppelen genoemd. De strategie om van klimaatadaptatie een eigen beleidsveld te maken met eigen instrumenten krijgt weinig steun (zie echter Massey \& Huitema, 2016). Beide strategieën beogen klimaatkennisproductie meer vraaggestuurd te maken. Welke consequenties heeft dat?

Ik zie voor- en nadelen van zowel de strategie om klimaatverandering mee te koppelen als om er een eigen beleidsveld van te maken. Het transformatieperspectief biedt mogelijkheden voor reflectie op de sturing van kennis voor klimaatadaptatie. De huidige dominerende meekoppelingsstrategie kan een rijke lappendeken opleveren van allerhande adaptatie-initiatieven met snelle acceptatie van klimaatoverwegingen en kennis die beter toegesneden is op lokale behoeften. Echter, in het voorgaande is beargumenteerd dat de kennis die in meekoppelingsprocessen wordt geconstrueerd wel blindheid voor sommige klimaatrisico's met zich meebrengt. Door de dominante perspectieven in een bepaald beleidsveld, en door de institutionalisering van procedures van handelen, leidt meekoppelen ook tot cog- 
nitieve padafhankelijkheid. Mijns inziens heeft de meekoppelingsbenadering geen goed antwoord op de vraag hoe kennisproductie moet worden georganiseerd voor die problemen die nog geen duidelijke eigenaar hebben. In die gevallen zijn vraaggestuurde kennisontwikkeling en co-creatie niet vanzelfsprekend. Bovendien slaagt die benadering er niet goed in transparant te maken welke belangen er worden gediend met nagestreefde kennisagenda's en waarom sommige risico's onderbelicht blijven.

Om de problemen van blinde vlekken en cognitieve padafhankelijkheid te voorkomen ben ik van mening dat er meer institutionele verandering nodig is dan meekoppelen doet voorkomen. Het integreren van een verkenning naar klimaatkwetsbaarheden in de reeds verplichte milieueffectrapportage zou een eerste stap kunnen zijn om de set van klimaatoverwegingen op de politieke agenda te verbreden. De MER kijkt alleen wel naar effecten op en niet naar effecten van de leefomgeving. Radicalere veranderingen zouden een periodieke herbeoordeling van de gevolgen van klimaatverandering voor kwetsbare sectoren kunnen verplichten. Dat zou een meer omvattend beeld opleveren van toekomstige klimaatrisico's. Engeland was daar een voorbeeld van, hoewel lokale klimaatkennisproductie daar wel is komen stil te staan sinds het ambitieuze reguleringskader uit de Climate Change Act deels is ontmanteld (Lorenz, Dessai, Forster, \& Paavola, 2017). Er zou een expertorganisatie kunnen worden opgezet om die beoordeling kritisch te beoordelen. Het openbaar maken van deze rapporten zou aanleiding kunnen geven voor een breder debat over de vraag welke klimaatrisico's daadwerkelijk van belang zijn en welke onderwerp moeten zijn van collectieve inspanningen.

\section{Literatuur}

Boezeman, D. (2015). Transforming adaptation: Authoritative knowledge for climate change governance. Nijmegen: Radboud University.

Boezeman, D. (2016). Understanding the transformation of climate futures: A conceptual framework illustrated with urban adaptation policy. Futures, 76, 30-41. http://doi.org/ 10.1016/j.futures.2015.07.008

Boezeman, D., Vink, M., \& Leroy, P. (2013). The Dutch Delta Committee as a boundary organisation. Environmental Science and Policy, 27, 162-171. http://doi.org/10.1016/j. envsci.2012.12.016

Boezeman, D., Vink, M., Leroy, P., \& Halffman, W. (2014). Participation under a spell of instrumentalization? Reflections on action research in an entrenched climate adaptation policy process. Critical Policy Studies, 8(4), 407-426. http://doi.org/10.1080/ 19460171.2014.950304

Charmaz, K. (2014). Constructing grounded theory. London: Sage.

Clarke, A.E., \& Star, S.L. (2008). The social worlds framework: A theory/methods package. In E.J. Hackett, O. Amsterdamska, M. Lynch, \& J. Wajcman (Eds.), The handbook of science and technology studies (pp. 113-137). Cambridge, MA: MIT Press.

Jasanoff, S. (2010). A new climate for society. Theory, Culture \& Society, 27(2-3), 233-253. http://doi.org/10.1177/0263276409361497

Jasanoff, S., \& Wynne, B. (1998). Science and decision making. In S. Rayner \& E. Malone (Eds.), Human choice and climate change, vol. 1: The societal framework (pp. 1-87).

Columbus: Battelle Press. 
Kirchhoff, C.J., Lemos, M.C., \& Dessai, S. (2013). Actionable knowledge for environmental decision making: Broadening the usability of climate science. Annual Review of Environment and Resources, 38(1), 393-414. http://doi.org/10.1146/annurev-environ-022112 $-112828$

Klinenberg, E. (2015). Heat wave: A social autopsy of disaster in Chicago (2nd ed.). Chicago: University of Chicago Press.

Lorenz, S., Dessai, S., Forster, P.M., \& Paavola, J. (2017). Adaptation planning and the use of climate change projections in local government in England and Germany. Regional Environmental Change, 2(17), 425-435. http://doi.org/10.1007/s10113-016-1030-3

Massey, E., \& Huitema, D. (2016). The emergence of climate change adaptation as a new field of public policy in Europe. Regional Environmental Change, 16(2), 553-564. http:// doi.org/10.1007/s10113-015-0771-8

Metze, T., \& Turnhout, E. (2014). Politiek, participatie en experts in de besluitvorming over super wicked problems. Bestuurskunde, 2, 3-11.

Rayner, S. (2012). Uncomfortable knowledge: The social construction of ignorance in science and environmental policy discourses. Economy and Society, 41(1), 107-125.

Sarewitz, D., \& Pielke, R.A. (2007). The neglected heart of science policy: Reconciling supply of and demand for science. Environmental Science and Policy, 10(1), 5-16. http://doi. org/10.1016/j.envsci.2006.10.001

Scott, J.C. (1998). Seeing like a state: How certain schemes to improve the human condition have failed. New Haven: Yale University Press.

Shackley, S., \& Wynne, B. (1996). Representing uncertainty in global climate change science and policy: Boundary-ordering devices and authority. Science, Technology \& Human Values, 21(3), 275-302. http://doi.org/10.1177/016224399602100302

Termeer, C., Dewulf, A., Rijswick, H. van, Buuren, A. van, Huitema, D., Meijerink, S., \& Wiering, M. (2011). The regional governance of climate adaptation: A framework for developing legitimate, effective, and resilient governance arrangements. Climate Law, 2(2), 159-179. http://doi.org/10.3233/CL-2011-032 